\title{
PANORAMA DE LINGÜÍSTICA Y TRADUCTOLOGÍA. APLICACIONES A LOS ÁMBITOS DE LA ENSEÑANZA DEL FRANCÉS/LENGUA EXTRANJERA Y DE LA TRADUCCIÓN (FRANCÉS-ESPAÑOL) \\ Elena Echeverría Pereda \\ Universidad de Málaga
}

Panorama de Lingüistica y Traductología. Aplicaciones a los ámbitos de la enseñanza del francés/ lengua extranjera y de la traducción (francés-español).

Autores: Nicolás A. Campos Plaza y Emilio Ortega Arjonilla. Atrio Editorial-Servicio de Publicaciones de la Universidad de Castilla-La Mancha, Granada, 2005.

Reseña: Elena Echeverría Pereda (Universidad de Málaga).

$\mathrm{N}^{\circ}$ de páginas: 811.

Dieciséis capítulos y dos amplísimos anexos bibliográficos componen esta monografía colectiva firmada por Nicolás A. Campos Plaza, catedrático de Filología Francesa de la Universidad de Murcia, y Emilio Ortega Arjonilla, profesor titular de Universidad de Traducción e Interpretación de la Universidad de Málaga.

En el preámbulo a esta obra, los autores muestran sus intenciones sobre el porqué y el para qué de la publicación de esta monografía:

"¿Por qué hemos escogido el mundo de la francofonía? Por varias razones:

1. Porque es un ámbito que creemos conocer en profundidad desde una perspectiva académica y profesional, dada nuestra vinculación con la enseñanza universitaria de la lengua francesa, de la lingüística francesa y de la traducción (francés-español).

2. Por consideramos que igual que no se puede entender la situación actual de los estudios lingüísticos y traductológicos sin atender a las aportaciones que desde el mundo anglosajón se han hecho a estas áreas de conocimiento, tampoco es posible entender el panorama actual sin detenernos en el estudio de las escuelas y/o tendencias que han tenido su origen en el mundo francófono y/o hispanohablante" (cf. preámbulo, págs. XVII-XVIII)

A continuación, en el mismo preámbulo, los autores advierten sobre la imposibilidad de ofrecer un panorama completo de la Lingüística francesa y 
francófona y de los Estudios de Traducción e Interpretación dentro de la combinación francés-español sin hacer algunas acotaciones previas:

"No se escapa a nuestra consideración que se trata de una tarea difícil, casi imposible de culminar con éxito, si no tenemos en cuenta una serie de elementos que nos permitar acotar el objeto de estudio:

1. En primer lugar, pretendemos orientar al lector realizando un breve recorrido histórico por algunos de los hitos más representativos de la evolución de la lingüística y de la traductología hasta nuestros días, centrando nuestra atención, en la medida de lo posible, en discernir cuál ha sido el papel desempeñado por la comunidad francófona internacional en la definición del estado actual de los estudios lingüísticos.

2. En segundo lugar, pretendemos que este trabajo de síntesis teórica tenga aplicaciones prácticas en dos ámbitos específicos: la enseñanza del francés como lengua extranjera y el mundo de la traducción dentro de la combinación lingüística francés-español / español-francés.

3. En tercer lugar, ofrecemos un amplio anexo bibliográfico en el que demos cuenta, mediante su división en repertorios de bibliografía principal comentada y bibliografía complementaria por temas, de las aportaciones de los autores más relevantes en cada una de las materias tratadas" (cf. preámbulo, pág. XVIII)

La intención de los autores se resume en el párrafo final de este preámbulo (pág. XIX):

"La empresa creemos que ha valido la pena, siempre y cuando el lector encuentre en las páginas que siguen una carta de navegación para orientarse en este entramado de escuelas y tendencias que constituyen, siguiendo a Virgilio Moya (2004), una auténtica selva de la traducción, metáfora ésta que es ampliable al mundo de los estudios filológicos y lingüísticos.

\section{SOBRE EL CONTENIDO DE LA OBRA}

Esta obra aparece dividida en dos primeras partes - que cuentan, cada una de ellas con 8 capítulos -; y dos anexos bibliográficos relativos a la primera parte (III parte) y a la segunda (IV parte). Los títulos que componen estas cuatro partes son los que se detallan a continuación. 
I Parte: PANORAMA DE LA LINGÜÍSTICA FRANCESA Y FRANCÓFONA. Aplicaciones a la enseñanza del francés/lengua extranjera.

Esta primera parte cuenta con 8 capítulos (numerados del 1 al 8). Los títulos de éstos se detallan a continuación:

Capítulo 1. Filología y Lingüística francesas. Delimitación conceptual. Capítulo 2. Aproximación a la historia de la Lingüística: del mundo clásico al siglo XX.

Capítulo 3. Descripción lingüística y formal de la lengua francesa (1): los componentes fónicos, morfológicos, sintácticos y morfosintácticos.

Capítulo 4. Descripción lingüística y formal de la lengua francesa (2): el componente semántico, la enunciación y la coenunciación. El marco de la pragmática.

Capítulo 5. Descripción lingüística y formal de la lengua francesa (3): el marco enunciativo y el de la lingüística textual.

Capítulo 6. La Lingüística aplicada a la enseñanza de la lengua francesa (1): reflexiones teóricas y metodológicas.

Capítulo 7. La Lingüística aplicada a la enseñanza de la lengua francesa (2): la gramática como soporte de la enseñanza-aprendizaje del francés.

Capítulo 8. La Lingüística aplicada a la enseñanza de la lengua francesa (3): propuestas didácticas de enseñanza del francés/lengua extranjera.

II Parte: PANORAMA DE LA TRADUCTOLOGÍA FRANCÓFONA E HISPANOHABLANTE. Aplicaciones a la enseñanza y a la práctica profesional de la traducción (francés-español / español-francés)

Esta segunda parte cuenta con 8 capítulos (numerados del 9 al 16). Los títulos de éstos se detallan a continuación:

Capítulo 9. El mundo de la traducción y de la traductología (1): antecedentes históricos y situación actual.

Capítulo 10. El mundo de la traducción y de la traductología (2): algunos debates recientes en la traductología actual.

Capítulo 11. El mundo de la traducción y de la traductología (3): una Torre de Babel conceptual. La definición de los términos traducción y traductología.

Capítulo 12. La traductología, una ciencia social (1): la traducción entendida como actividad.

Capítulo 13. La traductología, una ciencia social (2): la traducción entendida como proceso, el texto como unidad de traducción. 
Capítulo 14. La traductología, una ciencia social (3): la traducción entendida como producto.

Capítulo 15. La didáctica de la traducción (1): punto de encuentro entre teoría y práctica. Aplicaciones al ámbito de la traducción francés-español.

Capítulo 16. La didáctica de la traducción (2): traducción general y traducción especializada (francés-español / español-francés)

III Parte: Anexo bibliográfico sobre lingüística (general y aplicada) francesa y francófona

Este primer anexo bibliográfico cuenta con 18 apartados, que responden a los temas que se detallan a continuación:

1. La lingüística: objeto, métodos, ramas y relaciones de la lingüística con otras ciencias o disciplinas

2. Historia de la lingüística (1). Antecedentes de la lingüística

3. Historia de la lingüística (2). Siglo XIX

4. Historia de la lingüística (3). La lingüística del siglo XX: Ferdinand de Saussure

5. Historia de la lingüística (4). Escuelas lingüísticas derivadas de Ferdinand de Saussure

6. Historia de la lingüística (5). El estructuralismo americano

7. Historia de la lingüística (6). La lingüística generativo-transformacional

8. Historia de la lingüística (7). Otras corrientes lingüísticas del siglo XX

9. La lingüística diacrónica: historia de la lengua francesa

10. La lingüística sincrónica (1). Fonética y fonología de la lengua francesa

11. La lingüística sincrónica (2). Fonética de la lengua francesa

12. La lingüística sincrónica (3). Fonología y prosodia de la lengua francesa

13. La lingüística sincrónica (4). Sintaxis, morfosintaxis, semántica, pragmática, lingüística textual y análisis del discurso

14. Pragmática y análisis del discurso en lengua francesa

15. Texto y discurso en lengua francesa

16. La lingüística aplicada a la enseñanza de la lengua francesa

17. Repertorios bibliográficos de lingüística y filología francesas

18. Revistas de lingüística y filología francesas

IV Parte: Anexo bibliográfico sobre traductología francófona e hispanohablante

Este segundo anexo bibliográfico cuenta con 18 apartados, que responden a los temas que se detallan a continuación: 
1. Teoría General de la Traducción. Enfoques basados en presupuestos lingüísticos, culturales, traductológicos y/o interdisciplinares

2. Teoría, metodología e investigación traductológica y lingüística en el ámbito hispanofrancés. Obras colectivas y repertorios bibliográficos

3. Historia de la traducción e interpretación. Ámbito hispanofrancés

4. Didáctica general de la traducción y didáctica de la traducción general (francés-español)

5. Teoría, didáctica y práctica de la traducción (1). Ámbito literario

6. Teoría, didáctica y práctica de la traducción (2). Ámbitos científico, técnico y tecnocientífico. Traducción y nuevas tecnologías, TA, TAO y localización de software

7. Teoría, didáctica y práctica de la traducción (3). Ámbitos jurídico, jurado y judicicial. Ámbitos de las ciencias sociales y políticas, económicas y empresariales

8. Teoría, didáctica y práctica de la traducción (4). Traducción subordinada clásica (cómic, publicidad, etc,) y traducción audiovisual y multimedia

9. Teoría, didáctica y práctica de la interpretación. Interpretación de conferencias. Interpretación social o comunitaria y de lengua de signos

10. La profesión de traductor e intérprete: Reflexiones teóricas y aspectos de la práctica profesional.

11. Lingüística aplicada y traducción. Lingüística contrastiva y traducción (francés-español)

12. Recursos para el traductor en el ámbito hispanofrancés (1). Terminología, lexicografía y traducción

13. Recursos para el traductor en el ámbito hispanofrancés (2). Documentación y documentación aplicada a la traducción

14. Recursos para el traductor en el ámbito hispanofrancés (3). Manuales de ortografía, estilo y redacción de la lengua francesa y española

15. Recursos para el traductor en el ámbito hispanofrancés (4). Diccionarios generales y especiales de la lengua francesa

16. Recursos para el traductor en el ámbito hispanofrancés (5). Diccionarios generales y especiales de la lengua española

17. Recursos para el traductor en el ámbito hispanofrancés (6). Diccionarios bilingües generales (francés-español / español-francés)

18. Recursos para el traductor en el ámbito hispanofrancés (7). Recursos documentales electrónicos (diccionarios en internet) para la traducción especializada (francés-español / español-francés)

19. Recursos para el traductor en el ámbito hispanofrancés (8). Diccionarios monolingües (del francés o del español), bilingües especializados (francés-español / español-francés) y multilingües. Ámbito de las ciencias sociales, jurídicas y económicas 
20. Recursos para el traductor en el ámbito hispanofrancés (9). Diccionarios monolingües (francés) y bilingües (que lo incluyen). Ámbitos científico, técnico y tecnocientífico

21. Recursos para el traductor en el ámbito hispanofrancés (10). Diccionarios monolingües (español) y bilingües (que lo incluyen). Ámbitos científico, técnico y tecnocientífico

22. Recursos para el traductor en el ámbito hispanofrancés (11). Diccionarios bilingües especializados (francés-español/españolfrancés). Ámbitos científico, técnico y tecnocientífico

23. Recursos para el traductor en el ámbito hispanofrancés (12): Diccionarios multilingües especializados (que incluyen el francés y/o el español)

24. Recursos para el traductor en el ámbito hispanofrancés (13). Revistas de traducción

25. Recursos para el traductor en el ámbito hispanofrancés (14). Colecciones de traducción e interpretación (editoriales)

\section{ALGUNAS VALORACIONES PERSONALES}

El preámbulo y el índice, reproducido más arriba, son suficientemente esclarecedores sobre el contenido de la obra.

Huelga decir que esta obra resulta, a nuestro modo de ver, indispensable para los alumnos de Filología Francesa y de Traducción e Interpretación, sobre todo, con respecto a estos últimos, si dentro de sus lenguas de estudio se encuentran el francés y el español.

La obra se autoexplica, es diáfana, no conduce más allá de lo que apuntan los autores en el preámbulo, ni pretende sentar bases sin fundamento. Sencillamente pretende establecer una "carta de navegación" dentro del complejo mundo de la Lingüística (francesa y francófona), la Traducción y la Traductología contemporáneas, y, a nuestro modo de ver, lo consigue sobradamente. 